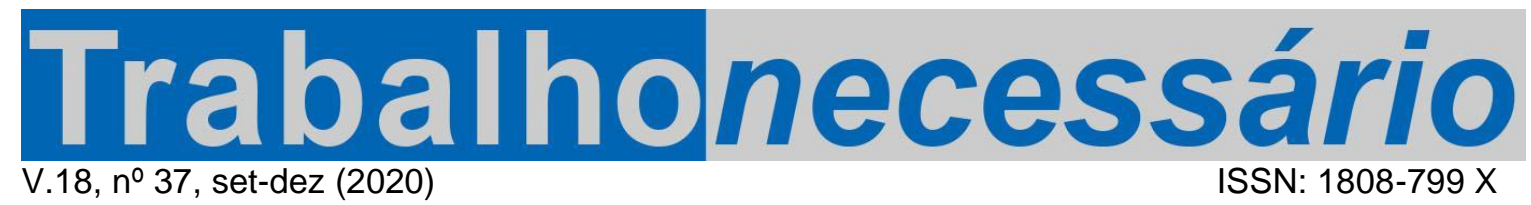

\title{
REFORMISMO E EDUCAÇÃO: A ESCALADA ULTRALIBERAL BRASILEIRA E SUAS REPERCUSSÕES EDUCATIVAS ${ }^{1}$
}

\author{
Victor Leandro da Silva²
}

\begin{abstract}
Resumo
O cenário recente da política brasileira vem sendo marcado por um forte ímpeto reformista ultraliberal, cujas consequências podem ser percebidas na recentemente aprovada reforma trabalhista. No entanto, para que tal empreitada se efetivasse, foi necessário promover também mudanças no sistema educativo, com vistas a propiciar as condições ideais para o desenvolvimento de tais diretrizes. Dessa forma, o presente texto tem por objetivo discutir de que maneira a educação encontra-se historicamente ligada às transformações do mundo do trabalho, bem com debater os elos que vinculam no Brasil a reforma do ensino médio e as mudanças deletérias dos direitos dos trabalhadores.
\end{abstract}

Palavras-chave: educação; mundo do trabalho; precarização; reforma do ensino médio; reforma trabalhista.

\section{REFORMISMO Y EDUCACIÓN: LA ESCALADA ULTRALIBERAL BRASILEÑA Y SUS REPERCUSIONES EDUCATIVAS \\ Resumen}

El escenario reciente de la política brasileña ha estado marcado por un fuerte impulso reformista ultraliberal, cuyas consecuencias se pueden ver en la reforma laboral recientemente aprobada. Sin embargo, para que este esfuerzo fuera efectivo, también era necesario promover cambios en el sistema educativo, con el fin de proporcionar las condiciones ideales para el desarrollo de tales pautas. Por lo tanto, este texto tiene como objetivo discutir cómo la educación está históricamente vinculada a los cambios en el mundo del trabajo, así como debatir los enlaces que vinculan la reforma de la educación secundaria en Brasil y los cambios perjudiciales en los derechos de los trabajadores.

Palabras clave: educación; mundo de trabajo; precariedad; reforma de la escuela secundaria; reforma laboral.

\section{REFORMISM AND EDUCATION: THE BRAZILIAN LIBERAL CLIMB AND ITS EDUCATIONAL REPERCUSSIONS \\ Abstract}

The recent scenario of Brazilian politics has been marked by a strong ultraliberal reformist impetus, whose consequences can be perceived in the changes in the Brazilian labor legislation, which aim mainly to meet the interests of large economic groups. However, for such an quest to take place, it was also necessary to promote changes in the education system, in order to provide the ideal conditions for the development of such guidelines. Thus, the present text aims to discuss how education is historically linked to the transformations of the world of work, as well as to debate the links that bind in Brazil the reform of high school and the deleterious changes in labor rights.

Keywords: education; the world of work; precariousness; high school reform; labor reform.

\footnotetext{
${ }^{1}$ Artigo recebido em 27/04/2020. Primeira Avaliação em 01/06/2020. Segunda Avaliação em 04/06/2020. Aprovado em 16/07/2020. Publicado em 25/09/2020.

DOI: https://Doi.org/10.22409/TN.V18I37.42365

${ }^{2}$ Graduado em Filosofia pela Universidade Federal do Amazonas - UFAM / Brasil. Doutor em Sociedade e Cultura na Amazônia pela Universidade Federal do Amazonas - Brasil. Professor Adjunto da Universidade do Estado do Amazonas - Brasil. E-mail: viktorleandro@hotmail.com ORCID: 0000-0002-9758-5249. Lattes: http://lattes.cnpq.br/960788003958929.
} 


\section{Introdução}

É sabida, pelo menos desde $A$ República de Platão, a relevância dos processos educativos para a constituição de um projeto sistemático de ordenamento social. É impossível construir qualquer proposta de organização em sentido amplo sem que a pedagogia em vigor participe de tais objetivos, razão pela qual esta se converte em um sistema integrado e também num agente profundo das mudanças ocorridas em cada bloco histórico.

As relações de trabalho, que na teoria marxista sedimentam a sociedade, por força dessa característica, atuam em forte relação com o que é preconizado nas práticas dos educadores. Desse modo, toda mudança estrutural trabalhista deve atravessar também as normas determinadas nas teorias pedagógicas.

No Brasil contemporâneo, a escalada ultraliberal tem se notabilizado pelo forte apelo na educação, colocando-a como uma peça-chave na imposição dessa nova ordem. Assim, a compreensão dos novos rumos do país não pode ser feita sem o debate acerca de suas implicações educativas, as quais, uma vez articuladas ao mundo do trabalho, permitem analisar profundamente o panorama das mudanças estruturais postas em curso.

Porém, antes de adentrar nessa problemática, e a fim de melhor situá-la no momento em que estamos, faz-se necessário discutir o percurso percorrido pelos vínculos entre trabalho e educação, o qual nos conduzirá, inevitavelmente, ao estudo a respeito da precarização proletária e seu mais recente movimento de uberização.

\section{Trabalho e educação: uma relação necessária}

Nas últimas décadas, a primazia do trabalho para a ordenação social vem sendo contestada fortemente, sob o argumento de se configurar numa teorização ultrapassada e anacrônica. No entanto, as configurações mais recentes e as tendências de desenvolvimento do mundo do trabalho e suas consequências apontam justamente para a direção oposta, em especial no Brasil, onde a retomada do projeto ultraliberal, após um átimo de iniciativas progressistas, vem trazendo sensíveis mudanças na cena trabalhista do país. 
Nesse contexto, cabe mais uma vez retomar a tradição marxista e relembrar os pontos nela que centralizam o trabalho dentro do conjunto da práxis humana, e o remetem, como bem observam Braz e Netto (2012) ao campo fundamental de constituição do indivíduo no que tange ao seu ser social. Seguindo por esse percurso, ambos enfatizam que foi devido ao trabalho que,

Os membros dessa espécie [humana] se tornaram seres que, a partir de uma base natural (seu corpo, suas pulsões, seu metabolismo etc.), desenvolveram características e traços que os distinguem da natureza. Trata-se do processo no qual, mediante o trabalho, os homens produziram-se a si mesmos (isto é, se autoproduziram como resultado de sua própria atividade) tornando-se - para além de seres naturais - seres sociais. Numa palavra, este é o processo da história (grifo do autor): o processo pelo qual, sem perder sua base orgânicosocial, uma espécie da natureza constituiu-se como espécie humana - assim, a história aparece como a história do desenvolvimento do ser social, como processo da humanização, como processo da produção da humanidade através da sua autoatividade; o desenvolvimento histórico é o desenvolvimento do ser social (BRAZ e NETTO, 2012, p. 49/50).

Na concepção advinda do pensamento de Marx, não é possível pensar o surgimento do ser humano sem estabelecer o trabalho como seu elemento básico de formação. Daí que não se trata de dizer que a sociedade simplesmente se reúne pelo trabalho no momento presente, nem tampouco que este é um determinante que está sendo ultrapassado. O trabalho, na verdade, é a forma própria de toda realização dos sujeitos, que apenas podem também modificar-se mediante sua atuação. Logo, quaisquer que sejam as mutações ocorridas no tecido social, estas têm vazão apenas se encontrarem no trabalho o ponto de esteio e sustentação que permita perpetrar tais mudanças. Do contrário, não se pode falar nem mesmo de um paradigma modificação, uma vez que a principal força atuante do processo encontra-se inerte.

Logo, para se entender as condições presentes no plano social, a análise das novas configurações do trabalho é de uma relevância imprescindível. Obviamente, isso inclui também, como componente de articulação, os processos educativos, que, ao longo de seu desenvolvimento, sofreram forte influência das mudanças ocorridas no mundo produtivo.

É o que bem observa o sociólogo Ricardo Antunes, ao articular as relações entre educação e trabalho, as quais, dentro da sociedade capitalista, adquiriram um imbricamento que torna ambos os campos interdependentes e colaboradores entre si da ordem econômica dominante. 
De acordo com sua análise, tais aproximações tiveram uma forte intensificação devido ao advento do modelo taylorista-fordista na produção, que passou a demandar um maior apuro quanto aos padrões formativos dos funcionários da fábrica. Com sua proposta de divisão rigorosa de tarefas e separação entre planejamento e execução, surgiu a necessidade de se gerar, no seio das camadas trabalhadoras, um conjunto de indivíduos aptos a atuar conforme essas designações. Obviamente, no que diz respeito às classes populares, caberia sobretudo torná-las capazes de executar funções especializadas e mecânicas, sem maior apuro teórico ou científico. Assim, dessa maneira, 0

taylorismo-fordismo colocou como horizonte um projeto de educação baseado em escolas técnicas ditas "profissionalizantes", cujo mote é formar os/as estudantes para o trabalho assalariado, ou melhor, formar a sua força de trabalho para o mercado, sendo que esse conhecimento deveria ser consumido pelas empresas como capital variável, como trabalho concreto urdido em trabalho abstrato. (ANTUNES, 2017, p. 2).

Trazendo, como consequência direta, uma nova configuração para os sistemas e tendências educativos:

Dentro dessa finalidade, o capitalismo concebido pelo desenho tayloriano-fordista colocou como horizonte à educação uma pragmática da especialização fragmentada. Uma educação moldada por uma concepção técnica que direciona a qualificação do trabalho nos limites da coisificação e da fragmentação impostas pelo processo de trabalho capitalista (ANTUNES, 2009a). A "escola ideal" para essa qualificação é a que promove o desmembramento entre conceito, teoria e reflexão (o trabalho intelectual), de um lado, e prática, aplicação e experimentação (o trabalho manual), de outro. (ANTUNES, 2017, p. 2).

Tal quadro posteriormente sofreu alterações, acompanhando o ritmo das mudanças que se foram instalando na esteira das inovações inseridas na ordem produtiva. Assim, com o advento da gestão toyotista, pautada nos princípios da acumulação flexível, que visava a atender uma lógica não mais de superprodução e sim de geração de mercadorias por demanda, houve a necessidade de se construir num novo modelo de trabalhador, muito mais afinado com as novidades científicas e com capacidades comportamentais destacadas como iniciativa, empreendedorismo, polivalência e potencial de liderança, o que, para além de um vocabulário atrativo, 
significava apenas um novo nome para o aprofundamento das formas de exploração da mais-valia.

Mais uma vez, as repercussões educativas são evidentes. Propostas voltadas para o aprender a aprender, que colocam o aluno apto a enfrentar o ritmo acelerado das novidades da tecnologia, começam a se tornar a palavra de ordem. O contato com aparelhos eletrônicos e digitais é estimulado desde cedo, bem como despontam as aulas interativas e os cursos que visam desenvolver a capacidade de invenção e a competitividade, buscando tornar os sujeitos cada vez mais adequados e atender as necessidades ascendentes na fábrica.

Paralelamente a esses processos, e concorrendo para o estabelecimento de uma nova razão educativa, prolifera um movimento de expansão do mercado de serviços, que passa a ocupar um lugar cada vez mais importante no mundo econômico, de tal maneira que muitos autores começam a falar de uma sociedade pós-industrial, ou seja, em que a organização da fábrica possui um impacto secundário nas diversas transformações da sociedade, ficando estas subordinadas sobretudo ao que ocorre nesses novos ramos de atividade econômica, no que a educação também atua sob esse conjunto novo de diretrizes fundamentais.

Seguindo por esse percurso, surge aquilo que foi denominado por alguns como "sociedade do conhecimento", produto de uma era pós-industrial, em que se valorizariam, sobretudo, os conhecimentos adquiridos e a criatividade, em detrimento da mecanização de tarefas. Nesse panorama, também o ambiente e as relações de trabalho deveriam ser modificados, a fim de não colocar limites nas práticas inventivas, promovendo um forte movimento de flexibilização de normas.

Mas, o que se anunciava o alvorecer de uma época de ouro revelou-se apenas mais um agravante na já combalida condição dos trabalhadores. Uma perda progressiva de direitos e garantias sociais instalou-se em larga escala, resultando em um processo global de dilapidação do estatuto econômico da classe proletária.

Surgem daí novas configurações que, segundo Guy Standing, culminam na formação do precariado, o qual, conforme sua leitura, pode ser definido da seguinte maneira:

o precariado poderia ser descrito como um neologismo que combina o adjetivo "precário" e o substantivo relacionado "proletariado". Neste livro, o termo é frequentemente usado nesse sentido, embora tenha limitações. Podemos afirmar que o precariado é uma classe-em- 
formação, se não ainda uma classe-para-si, no sentido marxista do termo. (2014, p. 23).

Na visão de Standing, o precariado, que à época de seu texto ele constatou como ainda em formação, deveria ser assumido como uma classe nova e perigosa, posto ser menos organizada que o proletariado tradicional, e ser submetida a condições muito mais aviltantes que esta, no que a revolta se mostrava não só iminente, como também de consequências imprevisíveis.

No entanto, a visão de Standing está longe de ser unânime. Há questionamentos que apontam não apenas para determinadas fragilidades de sua construção conceitual, como também põem em dúvida a validade de se procurar uma nova definição para o fenômeno em voga, o qual, em visões dissonantes, é tido como já incorporado em definições consagradas da análise social.

Mais uma vez, recorremos a Ricardo Antunes, que, em O privilégio da servidão, apresenta suas oposições à categoria apresentada por Standing, a qual, segundo ele, advém de um erro de concepção, em que:

com esse desenho crítico - ainda que a descrição empírica de Standing seja ampla e com informações relevantes - sua análise confere estatuto de classe ao que de fato é uma parcela do proletariado, e a mais precarizada, geracionalmente jovem, que vive de trabalhos com maior grau de informalidade, muitas vezes realizando atividades parciais, por tempo determinado ou intermitente. A resultante desse equívoco analítico levou o autor, inclusive, a concebê-la como "uma classe perigosa", "em si" e "para si" diferenciada da classe trabalhadora. (ANTUNES, 2018, p. 58).

A posição de Antunes é bastante incisiva. A classe intitulada precariado na verdade é apenas um recorte do antigo conjunto proletário, e que já poderia ser identificado em épocas anteriores, só que com a diferença de que agora se encontra em processo de franca expansão, ou seja, os movimentos de precarização do trabalho estão numa linha ascendente. Assim, dentro do conjunto dessas razões, segundo o sociólogo brasileiro, o entendimento acerca do precariado se forma de maneira bastante equivocada.

De qualquer forma, o que fica claro, tanto nas discussões de Standing quanto de Antunes, é que há, dentro do cenário mundial do mundo do trabalho, uma progressão contínua das iniciativas de supressão dos direitos dos trabalhadores, bem como o agravamento de suas condições de atuação e de oportunidades, gerando uma 
condição cada vez mais aviltante e propensa a produzir um número cada vez maior de mazelas sociais.

Tais processos, já emergidos e consolidados no século $\mathrm{XX}$, adquirem, com o desenvolvimento das teletecnologias, novos patamares que apontam para uma completa dissolução dos vínculos basilares que orientam as relações outrora constitutivas do trabalho, cujo resultado é o abandono das políticas de seguridade social que antes ofertavam garantias mínimas para os trabalhadores.

Agora, o que se encontra em evidência é o movimento intitulado uberização, cujo nome alude à famosa empresa ligada ao modelo de economia de compartilhamento, na qual se usa "a internet para conectar consumidores com provedores de serviço para trocas no mundo físico, como aluguéis imobiliários de curta duração, viagens de carro ou tarefas domésticas" (SLEE, 2017, p. 21). No caso da Uber, o serviço oferecido é o de intermediação entre motoristas e passageiros, que podem trafegar pela cidade a custos módicos, enquanto do outro lado tem-se um indivíduo com a opção de utilizar seu carro para adquirir renda. Um cenário bastante animador, não fosse pelo fato de que o que se esconde por trás dele é uma grande corporação cuja finalidade é aquela comum a todas as suas semelhantes, ou seja, a de obter o máximo de lucro para suas operações mediante a exploração dos trabalhadores.

A diferença, no caso, encontra-se nos meios empregados para atingir esse objetivo, que são, se não inéditos historicamente, ao menos articulados de maneira inovadora. A empresa consegue combinar de modo surpreendentemente novo a ausência de regulação e taxas pelos órgãos competentes e uma contínua exploração e controle via tecnologia do regime de trabalho, no que o motorista, colocado pretensamente na condição de autoempreendedor, vê-se obrigado a seguir normas extremamente rígidas quanto as suas atividades, sob pena de não ser mais admitido como membro da suposta comunidade livre. Tudo isso com a vantagem - para a empresa - de não ter de arcar com nenhuma das garantias trabalhistas, uma vez que "a classificação como contratante independente livra a companhia de ter de pagar por direitos trabalhistas e de ter de respeitar os padrões de emprego. O risco é inteiramente empurrado para o contratado" (SLEE, 2017, p. 134).

O que é importante observar no sistema envidado pela Uber é o quanto este modifica um item estrutural que irá ter consequências imensas para a organização do 
mundo do trabalho. Em termos estritos, o que ela promove como grande mudança é a supressão - tanto em termos jurídicos, como também personalísticos - da figura dos patrões. Logo, cria-se um mecanismo no qual não só não há a quem recorrer para garantir determinados direitos inerentes às classes trabalhadoras, como também não aparece mais o responsável por obter ganhos a partir da exploração do trabalho. Sobre a tela dos telefones móveis, o que se tem é tão apenas um aplicativo e seus comandos, e não mais um chefe. Dessa forma, tudo o que resta ao motorista é conformar-se ao que é estabelecido por essa mão invisível, ao passo em que deve ele próprio estabelecer-se como o seu único provedor aceitável, a quem compete não apenas conceder sua força produtiva, mas também providenciar os meios para sua atividade - compra e manutenção de automóveis, combustíveis e outros.

Como resultado, o que se tem é a diminuição praticamente absoluta de toda e qualquer garantia de bem-estar para os que atuam como operários nesse negócio. Férias e licenças médicas sequer podem ser pensadas. Muito menos é possível exigir a adesão das empresas a um sistema de aposentadoria. Tudo vai por conta própria. E, uma vez estando incapacitado para o trabalho, muitas vezes devido a este, o que resta ao trabalhador é tão somente relegar-se ao mais completo abandono, enquanto os executivos de compartilhamento ampliam vertiginosamente suas finanças.

Obviamente, a expansão desse modelo, por força de suas vantagens para o capital, tem-se tornado endêmica e atingido setores cada vez maiores da economia, o que, para que ocorra de maneira mais eficiente, requer que sejam repensadas as condições legais e políticas das diversas sociedades. No Brasil, tais processos de ajustamento tiveram início em 2016, numa ação que envolveu e continua a envolver de maneira coordenada mudanças no campo da educação e das leis trabalhistas, as quais, quando postas em exame, revelam um projeto sólido de recrudescimento do trabalho precarizado, cujo expansionismo encontra amparo na ascensão em larga escala das crenças ideológicas ultraliberais.

\section{Duas reformas, um objetivo}

Tão logo assumiu a presidência da república, em 12 de maio de 2016, a gestão liderada por Michel Temer tratou de pôr em prática o projeto de instituir de forma contundente as políticas ultraliberais no Brasil, as quais estavam orientadas, como 
não poderia deixar de ser, por uma forte redução dos investimentos públicos e por iniciativas que visavam desregular os diversos setores da economia, em especial no que dizia respeito à condição dos trabalhadores, num movimento que teve como fato principal a reforma trabalhista, assinada em julho de 2017.

Entretanto, meses antes desse evento crucial para a inserção do país nos rumos da uberização, um outro fato seria precursor desse cenário social precarizado. Trata-se da Medida Provisória 746, publicada em 23 de setembro de 2016, posteriormente convertida na Lei 13.415, e que promovia a chamada reforma do ensino médio, a qual, diferentemente da trabalhista, foi posta em curso de maneira completamente vertical, sem a menor abertura para o diálogo com os diversos segmentos da sociedade.

Qual o sentido de tal atitude? Se considerarmos o contexto geral das mudanças pretendidas, esta ruma para um caminho bem definido. A reforma do ensino médio é estratégica não somente para inserir as políticas educativas na ordem ultraliberal do trabalho, mas também para sedimentar o terreno a fim de criar as condições formativas e culturais para que o ideário político-econômico pretendido fosse posto em vigor, no que as posições expressas na MP servem como evidência.

É o que se mostra desde a exposição de motivos, em que são evocadas as razões pelas quais a MP está sendo implementada, e onde aparece a intenção clara de adequar o que está sendo ensinado nas escolas com as diretrizes do mundo do trabalho. Para tanto, usa-se como argumento a percepção do estudante, ou seja, daquele que é o mais interessado no processo:

\begin{abstract}
Atualmente o ensino médio possui um currículo extenso, superficial e fragmentado, que não dialoga com a juventude, com o setor produtivo, tampouco com as demandas do século XXI. Uma pesquisa realizada pelo Centro Brasileiro de Análise e Planejamento - Cebrap, com o apoio da Fundação Victor Civita - FVC, evidenciou que os jovens de baixa renda não veem sentido no que a escola ensina. (EM 00084/2016/MEC).
\end{abstract}

Trata-se de uma estratégia bastante problemática, quando analisada mais de perto. É bastante óbvio concluir que ao aluno de baixa renda o ensino oferecido se revela desconectado com suas realidade e expectativa. Mas essa é uma consideração que deriva de diversos outros fatores, sendo que o principal deles é o estado de vulnerabilidade em que se encontra. Ao estudante que está em situação mais favorável, que tem meios para estudar visando ao ingresso no ensino superior e não 
precisa se preocupar de pronto em obter renda, a impressão sobre os conteúdos ministrados pode ser bastante diferente, e rumar para uma aceitação bem mais pacífica do ensino oferecido. Contudo, para além dessa discussão, o que é preciso destacar aqui é que tais justificativas presentes no texto são indicadores inequívocos de fortes influências extraeducativas em sua redação.

Essas mesmas influências se alastram pelas determinações mais pragmáticas da nova lei, que estabelecem um forte enxugamento do currículo a ser percorrido, no qual apenas as disciplinas de matemática, língua portuguesa e língua inglesa permanecem como obrigatórias. Obviamente, a opção pelo idioma estrangeiro obedece ao princípio de inserção do aluno no mundo tecnológico e da cultura dominante, para os quais o inglês é a língua oficial. Seguindo essa linha, disciplinas de imersão crítica aos processos sociais foram negligenciadas, notadamente sociologia e filosofia, cuja presença passou a depender do esforço diretivo das gestões estaduais. Como se vê, o que persevera é a visão unívoca e inconteste de um modelo de escola plenamente direcionado à ordem vigente.

No lugar de uma educação pluralista e ampla, serão oferecidas ao aluno visões parciais, travestidas de escolhas por interesse. Além dos reduzidos conteúdos da Base Nacional Comum Curricular (BNCC), o aluno poderá seguir por um dos chamados itinerários formativos - linguagens, matemática, ciências da natureza, ciências humanas e formação profissional. No entanto, o que não foi dito à sociedade nas propagandas governistas é que a oferta de tais itinerários dependerá das condições de cada sistema de ensino, que o fará mediante sua conveniência. Assim, dificilmente os estudantes poderão de fato optar livremente por qual percurso seguir, recebendo na verdade aquilo que tão só lhes é oferecido, de maneira assumidamente restrita.

No que tange à formação profissional, um fato chama a atenção. O texto considera que poderão ministrar aulas "profissionais com notório saber reconhecido pelos respectivos sistemas de ensino, para ministrar conteúdos de áreas afins à sua formação ou experiência profissional, atestados por titulação específica ou prática de ensino em unidades educacionais" (Art. 6², Lei 13.415), o que abre caminho não só para que indivíduos sem a devida formação docente atuem nos sistemas de ensino, fato que em si já é um problema, mas também definindo as diretrizes a serem adotadas nos processos formativos daí por diante, e que irão ter como foco tão 
somente o desenvolvimento da competência técnica, do saber fazer, em detrimento do debate sobre o significado social das práticas relativas às diversas profissões, as quais exigem uma muito maior imersão em problemas teóricos e aproximativos às questões sociais, o que, a considerar o perfil permitido dos professores ingressos, não será priorizado.

Eis aí um aspecto que se delineia como um ente totalizante do sentido da reforma que ora se implementa. A compreensão do processo educativo enquanto práxis humanizadora encontra-se obliterada pelo lema da aplicabilidade dos conhecimentos adquiridos, numa reedição ligeira e anacrônica do tecnicismo dos anos de chumbo, grande responsável por acentuar as desigualdades educativas até hoje vigentes.

Com isso, tem-se sedimentado o terreno ideológico em que irá avançar o projeto de repressão trazido pela nova legislação trabalhista, a qual não encontrará na população, devido ao cenário elaborado, focos significativos de resistência. Como bem nos lembra Bourdieu (2012), esse é um tipo de tarefa que se realiza sempre mediante a obtenção de anuência por parte dos oprimidos, que, no caso em questão, uma vez estando habituados à lógica exploratória no espaço da escola, naturalizamna e não se afetam em reproduzi-la no âmbito do trabalho, razão por que as alterações nos dois âmbitos estão sendo trabalhadas em conjunto.

Nisso se identificam algumas relações, afora aquelas mais de fundo, diretas entre a organização do ensino médio proposto e as normas para o trabalho definidas na lei № 13.467, de 13 de julho de 2017, que também se encontra pautada no princípio de uma suposta flexibilização, que nada mais é que uma forma de fazer com que o trabalhador ofereça mais trabalho em condições menos favoráveis, tal como na escola os estudantes precisarão ter um aprendizado melhor sem as mesmas condições e conteúdos de ensino. De igual maneira, a qualificação deficitária obtida na escola se coaduna com o tipo de trabalhador que passa a ser exigido, cuja desvinculação àquele que o emprega faz com que este deva procurar estar apto a desempenhar suas funções por conta própria, uma vez que o frágil vínculo entre eles não abre espaço para o custeio de iniciativas de capacitação profissional.

Por outro lado, a oferta de ensino em EaD prevista nas diretrizes curriculares nacionais para o ensino médio, homologadas por meio da Resolução 03, de 21 de novembro de 2018, constitui um símile das regulamentações quanto ao teletrabalho e 
à jornada intermitente, em que se é convocado ao posto tão somente quando houver necessidade, tal como o aluno em disciplinas a distância. Com isso, constroem-se indivíduos comportamentalmente adequados a conviver com uma oferta de condições favoráveis cada vez mais escassa e conforme interesses que lhes são alheios.

Já o afrouxamento das normas de ingresso na docência, que permite admitir professores com base no notório saber para aplicar determinadas formas de ensino técnico, relaciona-se bem às regras de terceirização, em que o trabalhador é convocado por uma empresa mediadora para cumprir uma determinada atividade, sem o mínimo de observância às suas aptidões por parte daqueles que recebem o serviço prestado, interessando tão somente o resultado final, que é o ganho econômico pretendido.

Todas essas alterações, todos esses movimentos de precarização da escola e do trabalho, rumam para o mesmo e único objetivo, traçado desde os primórdios da sociedade do capital: a manutenção da taxa de lucro por meio da produção de maisvalia absoluta e relativa, a qual vem se tornando uma tarefa cada vez mais difícil devido aos limites estruturais do capitalismo (NETTO e BRAZ, 2012), o que vem demandando medidas cada vez mais radicais e deletérias no que diz respeito à situação geral dos trabalhadores.

Se os professores, que também não escapam a essa lógica exploratória, irão ceder às pressões impostas por esse estado de forças, ainda não é possível prever. Contudo, certo é que estes se constituem como a última linha de resistência quanto a esses processos, no que a crítica e a organização de classe formam as armas mais incisivas e transformadoras.

\section{Considerações finais}

Ao tempo em que o presente texto era redigido inicialmente, tramitava em sua fase decisiva no senado federal a reforma da previdência, a qual teve sua promulgação efetivada em 12.11.2019. Com ela, não só o presente, mas principalmente o futuro dos trabalhadores será amplamente afetado pelo ciclo de reformas ultraliberais instituído no país nos últimos anos, o qual, além de prover uma trajetória degradante no mundo do trabalho, também comprometerá por completo os anos que restam aos indivíduos em suas aposentadorias. 
Desse modo, fecha-se um círculo de precarização do trabalho, que agora terá destituído as elaborações do estado de bem-estar social, deixando em seu lugar tão somente um rastro de empobrecimento e de produção contínua de desigualdades entre a maioria esmagadora dos trabalhadores e a mínima classe dos donos do capital.

Contudo, ainda é cedo para afirmar que tal movimento encontra-se plenamente estabelecido. Em países onde tais reformas foram implantadas há mais tempo, têm ocorridos protestos cada vez mais incisivos contra elas. Assim, ainda existe um largo horizonte de disputa. Porém, quaisquer que sejam as perspectivas, a educação seguirá sendo o alicerce de seu advento, para o qual se procurará sempre, por meio de mudanças no sistema educativo, direcionar os rumos da nação. Nisso, tem-se comprovada de maneira inequívoca sua importância econômica e política, para a qual os educadores precisam estar atentos permanentemente.

\section{Referências}

ANTUNES, Ricardo. Da Educação Utilitária Fordista à da Multifuncionalidade Liofilizada. 38 ${ }^{\text {a }}$ Reunião Nacional da ANPEd - 01 a 05 de outubro de 2017 - UFMA - São Luís/MA. Disponível em: http://38reuniao.anped.org.br/sites/default/files/resources/programacao/trabalhoenco m_38anped_2017_gt11_textoricardoantunes.pdf. Acesso em 11.11.2019.

. O Privilégio da Servidão. São Paulo: Boitempo Editorial, 2018.

BOURDIEU, Pierre. O Poder Simbólico. Rio de Janeiro: Bertrand Brasil, 2012.

BRASIL. Exposição de motivos n. 00084/2016/MEC. Disponível em: http://www.planalto.gov.br/ccivil_03/_ato2015-2018/2016/Exm/Exm-MP-746-16.pdf. Acesso em 11.11.2019.

Lei 13.415, de 16 de fevereiro de 2017. Disponível em: http://www.planalto.gov.br/ccivil_03/_Ato2015-2018/2017/Lei/L13415.htm. Acesso em 11.11.2019.

Lei 13.467, de 13 de julho de 2017. Disponível em: http://www.planalto.gov.br/ccivil_03/_ato2015-2018/2017/lei//13467.htm. Acesso em 11.11.2019.

Disponível

Resolução 03, de 21 de novembro de 2018 - Ministério da Educação. /asset_publisher/Kujrw0TZC2Mb/content/id/51281622. Acesso em 11.11.2019. 
NETTO, José Paulo; BRAZ, Marcelo. Economia Política: Uma Introdução Crítica. São Paulo: Cortez, 2012.

SLEE, Tom. Uberização: A Nova Onda do Trabalho Precarizado. São Paulo: Elefante, 2017.

STANDING, Guy. O Precariado: A Nova Classe Perigosa. Belo Horizonte: Autêntica Editora, 2014. 